\title{
Editorial: The Lessons of Pittsburgh
}

\author{
C. C. Chancey \\ University of Northern lowa \\ Cedar Falls, lowa 50614-0150 USA
}

STEM graduates, those with degrees in the sciences, technology, engineering and mathematics, are vital in high-tech workforce development. Even though they make up only $19 \%$ of all undergraduate degrees in the US, STEM degree holders play an outsize role in the nation's economic engine. Pittsburgh, a "rust-belt" manufacturing town in western Pennsylvania, offers an object lesson in this regard.

Recently the Financial Times of London, in an in-depth series of articles "Is America Working?" profiled Pittsburg in a December 12, 2011, article entitled "Steel City' Pittsburgh Develops a Soft Side." 1

Though Pittsburgh had once produced half of all steel in the US, by 1979 foreign competition and out-dated technology had caught up with the industry. The city bled jobs, and businesses tied to steel's supply chain died. Between 1990 and 2010, Pittsburgh lost $20 \%$ of its population-a harbinger, all too often, of further economic collapse. But local unemployment went down, from $6.4 \%$ in 1990 to $5.0 \%$ in 2011 . The local economy clearly didn't collapse. Why?

In part because of a strong partnership between the city's universities and the city government. Pittsburgh consciously set out to rebalance its local economy with much less steel and with far more industries in the areas of advanced manufacturing and health care. Entrepreneurship in STEM areas, fostered for example by Carnegie Mellon University, was crucial to rebuilding the local economy.

The two over-arching goals of Carnegie Mellon's Project OLYMPUS ${ }^{2}$ have local economic concerns at the fore front:

- Bridging the Gap between CuttingEdge University Research/Innovation and Economy-Promoting Commercialization For the Benefit of our Communities, and

\footnotetext{
${ }^{1}$ http://www.ft.com/intl/usworks

${ }^{2}$ http://olympus.cs.cmu.edu/
}

- Creating a Climate, Culture \& Community to Enable Talent and Ideas to Grow in the Region.

As OLYMPUS explains it: "Project Olympus is a front door for facilitating university and industry partnerships, and a hub for connecting students and faculty from multiple disciplines with each other and with the broader innovation community. At its core is a prestigious "proof-of-concept" Innovation Lab where students, graduates and Innovation Fellows team with faculty, Olympus Executive Board and Advisory Cabinet members, and a network of partners to explore commercial potential of the university's world-class research through focused PROBEs (PROBlem-oriented Explorations). Guidance is provided at every stage by the Olympus Business Advisor, and Embedded Entrepreneur working together with teams of MBA students.

$\begin{array}{cccr} & \text { Olympus } & \text { CONNECTS } & \text { events } \\ \text { provide } & \text { an } & \text { environment } & \text { for }\end{array}$ entrepreneurially-minded students to meet, dream, and do. The popular Show and Tells provide a window into the many exciting developments on campus, further creating new and vital connections and collaborations with the broader community. Resulting collaborations help accelerate the process of transforming ground-breaking research and great ideas to viable commercialization; in turn, ideas and resources flow back to the university research enterprise to stimulate further innovation, thus creating a virtuous cycle."

Project OLMYPUS is one example of several local partnerships between Pittsburgh and its universities and community colleges that have helped revive the city, recently voted the US's "most livable" metropolitan area.

Pittsburgh's foresight in leveraging its STEM graduates is an example of what can be done even in the face of challenging circumstances. It should be a model for other cities trying to remake themselves for the $21^{\text {st }}$ Century. 